\title{
Relationship between stand structures and rainfall partitioning in dense unmanaged Japanese cypress plantations
}

\author{
Seonghun JeOnG ${ }^{\mathrm{a}}$, Kyoichi OTsuki ${ }^{\mathrm{b}, \dagger}$ and Moein FARAHNAK ${ }^{\mathrm{a}}$ \\ ${ }^{a}$ Graduate School of Bioresources and Bioenvironmental Sciences, Kyushu University, Fukuoka 812-8581, Japan \\ ${ }^{\mathrm{b}}$ Kasuya Research Forest, Kyushu University, Sasaguri, Fukuoka 811-2415, Japan
}

\begin{abstract}
The research on the relationship between stand structures and rainfall partitioning (RP) of gross rainfall $(G R)$ into throughfall $(T F)$, stemflow $(S F)$, and interception loss $(I L)$ was conducted in the two dense unmanaged Japanese cypress plots at an age of 33 years with stand density of $2500 \mathrm{stems} \mathrm{ha}^{-1}$, and the results were compared with the previous studies. The results showed that (1) $T F / G R$ significantly decreased, but $S F / G R$ and $I L / G R$ significantly increased with increasing stand density, which confirms that stand density is an informative stand structure factor for all the RP components in coniferous plantations. In addition to stand density, canopy cover ratio and storage capacity could also be influential stand structure factors for RP. (2) Having the highest stand density, $T F / G R$ were the lowest class and $S F / G R$ and $I L / G R$ were the highest class in the two study plots. In detail, however, the plot with smaller stand with denser and thicker dead branch layers had the exceptionally low $T F / G R$ compared with the other plot, but $S F / G R$ in both plots were almost identical. (3) $T F / G R$ decreased with increasing number of dead branches possibly because of increasing rainwater interception by dead branches, while it increased with increasing vertical dead branch space possibly because of increasing rainwater splash by dead branches. $S F / G R$ could increase by dead branches possibly because of the additional gain of rainwater by the dead branches. However, the number of dead branches did not affect $S F / G R$ possibly because the dead branches generating $S F$ could be limited to the upper dead branches. These findings will contribute new information to the studies on RP in coniferous plantations and guide better silvicultural practices for effective forest ecological services.
\end{abstract}

Key words: Dead branch, Interception loss, Stand density, Stemflow, Throughfall

\section{Introduction}

Rainfall partitioning (RP) plays an important role in ecological, hydrological, and biogeochemical functions of forests (e.g., Llorens and Domingo, 2007; Sadeghi et al., 2018). When gross rainfall $(G R)$ begins, the initial interaction occurs at forest canopy. $G R$ is partitioned into (1) throughfall $(T F)$ freely falling through the gaps and dripping and splashing from the canopy (2) stemflow $(S F)$ flowing down the stem, and (3) interception loss $(I L)$ once retained in the canopy and evaporating back to the atmosphere (Levia et al., 2017). TF is a primary component of RP portioning from $60.0 \%$ to $85.0 \%$ of $G R$ in coniferous forests (Sun et al., 2014). Although $S F / G R$ accounts for less than $10 \%$ on average, it is highly dependent on tree species and their structure (Levia and Frost, 2003; Levia and Germer, 2015). IL amounts from $9 \%$ to $48 \%$ of GR (Hörmann et al., 1996). Since RP has such a great influence on forest water budget, an understanding of characteristics of each component of RP is important for balancing silvicultural practices and forest ecosystem services.

Previous studies addressed that RP is a complex process controlled by various factors such as meteorological conditions (e.g., evaporation rate, rainfall intensity and rainfall amount; Gash, 1979; Llorens et al., 1997; Komatsu et al., 2008) and

\footnotetext{
Received; July 3, 2018

Accepted; December 20, 2018

†Corresponding Author: otsuki@forest.kyushu-u.ac.jp

DOI: 10.2480/agrmet.D-18-00030
}

stand structures (e.g., stand density $(S D)$, basal area $(B A)$ and canopy cover (CC); Teklehaimanot et al., 1991; Komatsu et al., 2007, 2015; Molina and del Campo, 2012; Sun et al., 2015; Sun et al., 2017). The examination of RP in the regions where climate conditions (e.g., annual precipitation and seasonality of precipitation) are comparable, however, could reduce the effects of climate conditions and enable us to investigate the effects of forest structures with similar leaf phenology on RP (Komatsu et al., 2007, 2015; Sun et al., 2017).

In Japan, $67 \%$ of the land is covered by forest, of which $41 \%$ is occupied by plantations (Japan Forestry Agency, 2017). Japanese cedar (Cryptomeria japonica D. Don) and Japanese cypress (Chamaecyparis obtusa Endl.) are two dominant coniferous tree species occupying $44 \%$ and $25 \%$ of the plantations, respectively. A substantial number of these coniferous plantations have not been managed on account of the economic recession on forestry since the 1980s (Onda et al., 2010). As a result, these coniferous plantations have been kept under high $S D$ and densely covered by canopies, which could intercept more rainwater at the canopies and thus reduce water supply to the forest floor (Kuraji, 2003; Sun et al., 2015; Shinohara et al., 2015). Since the awareness on the adverse effects of these unmanaged coniferous plantations has been increasing, effective forest management for solving such problems and enhancing forest ecosystem services has become a pressing issue. Komatsu et al. (2015) highlighted the usefulness of $S D$ as a key forest inventory data for estimating $I L$ of these coniferous plantations in Japan. Sun et al. (2017) evaluated $S D$, $C C$, and $B A$ as the useful stand structure factors also obtained from 
the forest inventory to estimate $T F$ in these coniferous plantations in Japan, among which $S D$ was most highly correlated with $T F$.

Although the dataset of previous studies on RP in the above-mentioned coniferous plantations includes the data with various $S D$, there are few data with a $S D$ of $2500-3000$ stems ha $^{-1}$ which is a typical planting density for these coniferous species (Japan Forestry Agency, 2017). Shinohara et al. (2010) addressed that there was a possibility of appearing new stand structure factors affecting RP such as leaf area and dead branches in dense unmanaged coniferous plantations other than $S D$. Therefore, finding the relationships between all the components of RP and key stand structure factors in addition to $S D, C C$ and $B A$ including the data with a $S D$ of 2500 stems $^{-1}$ or more is required for better understanding of RP and better silvicultural practices for effective forest ecological services.

In this study, we observed all the components of RP and various stand structure factors in two nearby plots in a dense unmanaged Japanese cypress plantation with a $S D$ of 2500 stems $\mathrm{ha}^{-1}$ and set the following objectives:

(1) to see the difference of RP with the data reported in previous studies with a $S D$ ranging $300-2400$ stems ha $^{-1}$.

(2) to see the difference of RP in the dense unmanaged coniferous plantations with the same $S D$ but different stand structures.

(3) to see the new stand structure factors affecting RP in the dense unmanaged coniferous plantations.

\section{Materials and methods}

\subsection{Site description}

This study was conducted in an unmanaged 33-year-old Japanese cypress (Chamaecyparis obtusa Endl.) plantation at the Takada Experimental Site in the Kasuya Research Forest, Kyushu

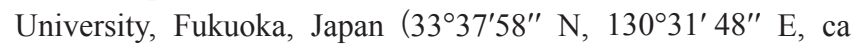
$100 \mathrm{~m}$ a.s.1.). The plantation has not been managed since planting with a $S D$ of 2500 stems ha $^{-1}$ in 1985 . The soil type is brown forest soil originated from serpentine bedrock (Kinoshita and Takimoto, 1936). The mean annual temperature and the mean precipitation were $17.1^{\circ} \mathrm{C}$ and $1634.3 \mathrm{~mm}$, respectively, recorded from 1986 to 2015 at a meteorological station $9 \mathrm{~km}$ southwest of the study site. Rainy season is from June to September, and snowfall rarely occurs.

Two $20 \mathrm{~m} \times 10 \mathrm{~m}$ study plots were established (Fig. 1, Table 1). They were approximately $50 \mathrm{~m}$ apart (hereafter P1 and P2). Both plots were relatively steep with slopes of 26 degrees. $S D$ of each plot was 2500 stems ha ${ }^{-1}$ containing 50 trees of Japanese cypress among which five trees had no leaves due to self-thinning (Fig. 1).

The stand structures are summarized in Table 1. The recommended $B A$, relative spacing $(R s)$, and relative yield index $(R y)$ indicating status of stocking for silvicultural practice of Japanese cedar and cypress plantations in Japan are $50 \mathrm{~m}^{2} \mathrm{ha}^{-1}$, $20 \%$, and 0.7 , respectively (Tange and Koike, 2016). Those variables in the plots were $65-85 \mathrm{~m}^{2} \mathrm{ha}^{-1}, 13-16 \%, 0.88-0.95$, respectively, which implies that both plots were overstocked. $C C$ and plant area index $(P A I)$, the variables indicating the status of canopy coverage by leaves, branches, and stems, were $99.3-99.6 \%$ and $5.6-6.4 \mathrm{~m}^{2} \mathrm{~m}^{-2}$, respectively, which implies that both plots were almost fully covered by the canopies.
Table 1. Stand structures of plot 1 (P1) and plot $2(\mathrm{P} 2)$.

\begin{tabular}{|c|c|c|}
\hline \multirow{2}{*}{ Stand structures } & P1 & $\mathrm{P} 2$ \\
\hline & Average \pm S.D. & Average \pm S.D. \\
\hline The number of trees $\left(N_{\text {tree }}\right)$ & 50 & 50 \\
\hline Tree age (years) & 33 & 33 \\
\hline Stand density $\left(S D\right.$, stems ha $\left.{ }^{-1}\right)$ & 2500 & 2500 \\
\hline Diameter at breast height $(D B H, \mathrm{~cm})$ & $17.7 \pm 4.1$ & $20.4 \pm 4.1$ \\
\hline Tree height $(H, \mathrm{~m})$ & $12.7 \pm 2.0$ & $15.4 \pm 2.0$ \\
\hline Stand volume $\left(S V, \mathrm{~m}^{3} \mathrm{ha}^{-1}\right)$ & 286.7 & 453.6 \\
\hline Basal area $\left(B A, \mathrm{~m}^{2} \mathrm{ha}^{-1}\right)$ & 64.9 & 85.2 \\
\hline Relative spacing index $(R s, \%)$ & 15.8 & 13.0 \\
\hline Relative yield index $(R y)$ & 0.88 & 0.95 \\
\hline Crown projection area $\left(C P A, \mathrm{~m}^{2}\right)$ & $4.8 \pm 1.8$ & $4.7 \pm 1.9$ \\
\hline Canopy cover ratio $(C C, \%)$ & $99.3 \pm 0.1$ & $99.6 \pm 0.1$ \\
\hline Plant area index $\left(P A I, \mathrm{~m}^{2} \mathrm{~m}^{-2}\right)$ & $5.6 \pm 0.2$ & $6.4 \pm 0.2$ \\
\hline
\end{tabular}

S.D. denotes standard deviation.

$R s$ indicates that the ratio of the mean distance between trees to the mean dominant tree height of the stand.

Considering these variables, $\mathrm{P} 2$ was slightly denser than that of P1 (Fig. 1, Table 1). Tree height and diameter at breast height $(D B H)$, the variables indicating tree size, were $19-20 \mathrm{~m}$ and $13-15 \mathrm{~cm}$, respectively, which indicates the tree size in P2 belongs to the highest class and that in $\mathrm{P} 1$ belongs to the middle class in the stand of their age in this area (Japan Forestry Agency, 1957).

The crown and live branch structures are given in Table 1 and Fig. 2. The average crown projection area $(C P A)$ was $4.8 \mathrm{~m}^{2}$ in $\mathrm{P} 1$ and $4.7 \mathrm{~m}^{2}$ in $\mathrm{P} 2$ and the average crown length was 2.8 in P1 and $3.0 \mathrm{~m}$ in P2. The average number of live branches $\left(\overline{N_{l b}}\right)$ and thickness of live branch layer were 15.7 branches $(21.8 \%$ of the total number of branch) and $2.8 \mathrm{~m}(22.3 \%$ of the tree height $)$ in P1 and 14.7 branches (23.6\% of the total number of branch) and $3.0 \mathrm{~m}(19.5 \%$ of the tree height $)$ in P2, respectively. The average number of live branches per unit length $\left(\overline{n_{l b}}\right)$ and vertical live branch space $\left(\overline{s_{l b}}\right)$ were 5.6 branches $\mathrm{m}^{-1}$ and $0.18 \mathrm{~m}$ in P1 and 4.9 branches $\mathrm{m}^{-1}$ and $0.20 \mathrm{~m}$ in $\mathrm{P} 2$, respectively. The results show that the crown and live branch structures were almost identical.

The dead branch structure is shown in Fig. 2. Since the trees in the plantation have not been pruned and dead branches of Japanese cypress tend not to fall naturally (Otake et al., 2007), the dead branches were densely distributed from the base of the crown to the nearby forest floor in each plot. The average number of dead branches $\left(\overline{N_{d b}}\right)$ and length of dead branch layer were 56.3 branches (78.2\% of the total number of branch) and $7.9 \mathrm{~m}(62.1 \%$ of the tree height) in P1 and 47.4 branches $(76.4 \%$ of the total number of branch) and $10.6 \mathrm{~m}(68.8 \%$ of the tree height $)$ in P2, respectively. The average number of dead branches per unit length $\left(\overline{n_{d b}}\right)$ and vertical dead branch space $\left(\overline{s_{d b}}\right)$ were 7.1 branches $\mathrm{m}^{-1}$ and $0.14 \mathrm{~m}$ in $\mathrm{P} 1$ and 4.5 branches $\mathrm{m}^{-1}$ and $0.22 \mathrm{~m}$ in $\mathrm{P} 2$, respectively. The results show that the dead branches in $\mathrm{P} 1$ were more densely and closely distributed than those in P2, despite the fact that the canopy in P1 was slightly sparser than that in P2 (Table 1).

\subsection{Measurements}

\subsubsection{Stand structure measurements}

$C C$ and $P A I$ were measured using a pair of LAI-2000 plant canopy analyzers (Li-COR Inc., Lincoln, NE, USA) and FV2000 (LI-COR). The measurements were conducted on an overcast 


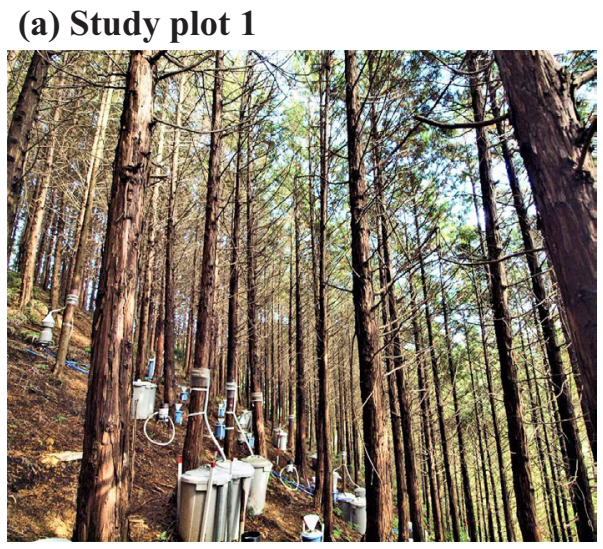

(a) Study plot 1

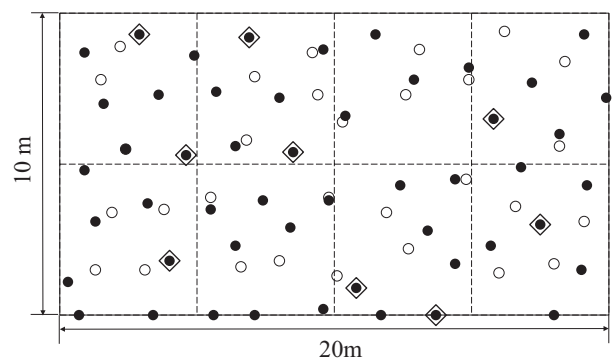

(b) Study plot 2

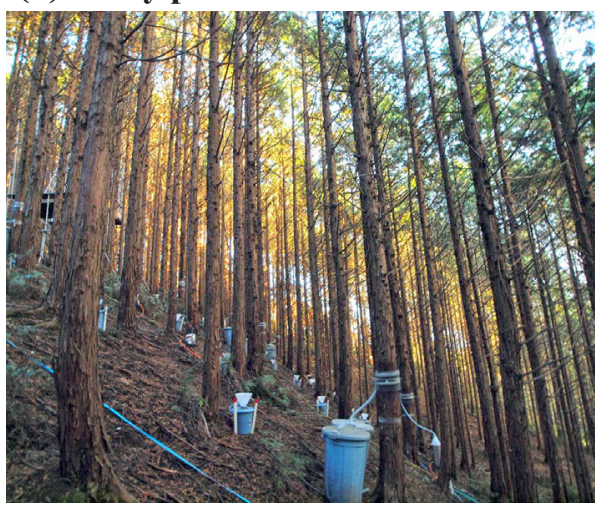

(b) Study plot 2

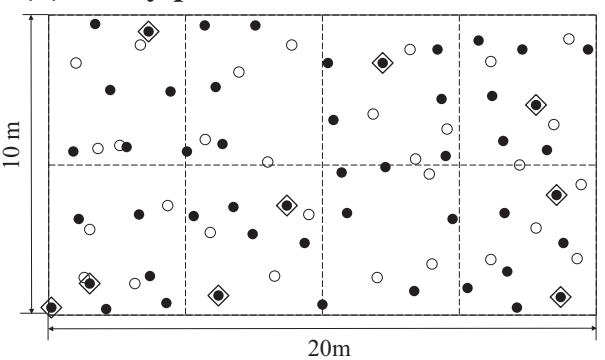

Fig. 1. Photos and measurement designs of the (a) study plot 1, and (b) study plot 2. The solid circles indicate trees, the diamonds shapes indicate stemflow measurement, and the open circles indicate funnel-type throughfall collectors. The dash lines denote the borders of the subplot of $5 \mathrm{~m} \times 5 \mathrm{~m}$.

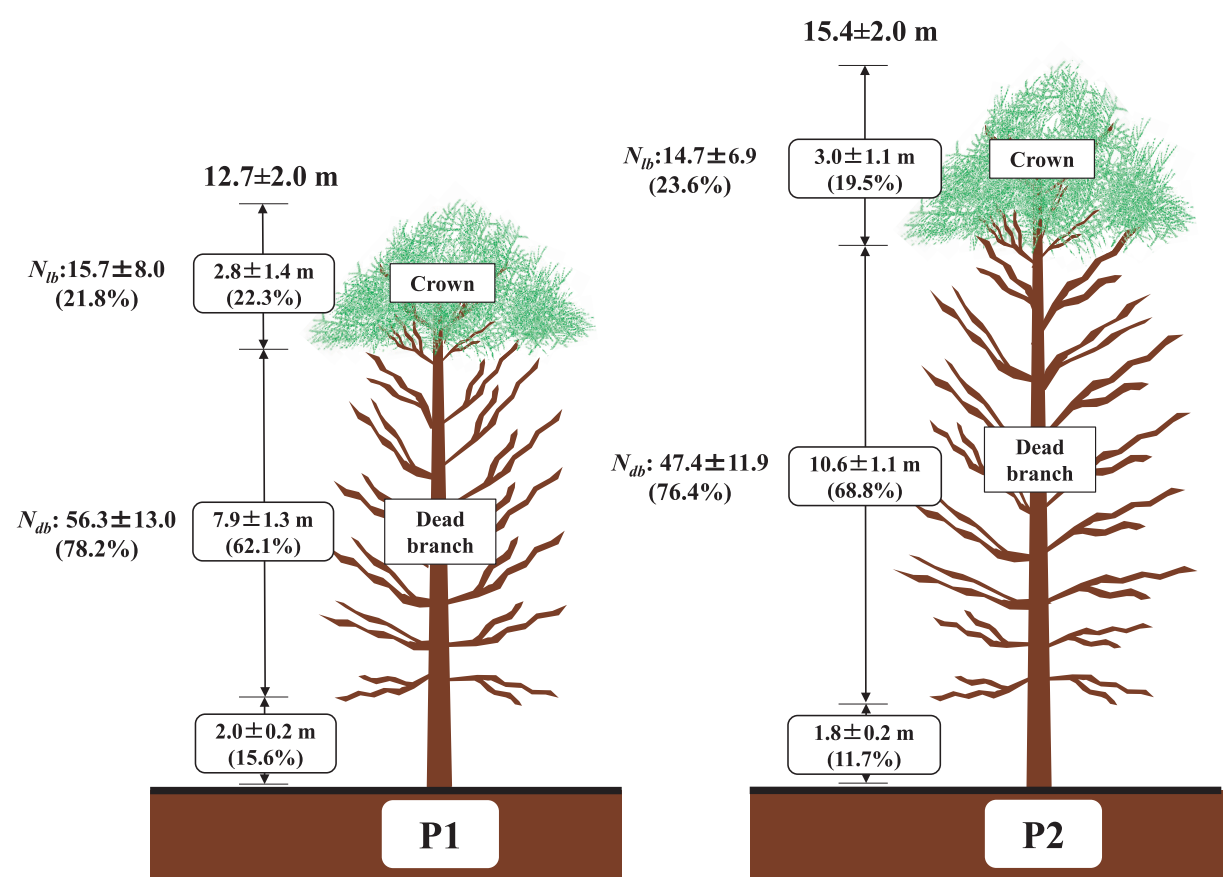

Fig. 2. Schematic diagrams of branch distribution in the study plot 1 (P1) and study plot 2 (P2). $N_{l b}$ and $N_{d b}$ denote the number of live branches and dead branches, respectively. Each number indicates the average \pm standard deviation of the number of branches and thickness of layers with their percentage of the total number of branches or tree height.

day to avoid the disturbance from direct sunlight. The free $T F$ coefficient $\left(C_{F T F}\right)$ was calculated using the following equation (Carlyle-Moses and Price, 1999; Shinohara et al., 2015):

$$
C_{F T F}=1-C C
$$

In this study, we regarded the visually detectable branches longer than about $50 \mathrm{~cm}$ with leaves as live branches and those without leaves as dead branches. Branch distribution was observed by counting the number of live and dead branches using a telescope and measuring the heights of tree top, lowest 
live branch, and lowest dead branch using a hypsometer (Haglöf Vertex IV-360, Haglőf Inc., Madison, MS, USA).

\subsubsection{Hydrometeorological measurements}

$G R$ was measured using a funnel-type rain collector (funnel diameter $=210 \mathrm{~mm}$ ) and a HOBO RG3-M tipping bucket rain gauge with a resolution of $0.2 \mathrm{~mm}$ (diameter $=154 \mathrm{~mm}$, Onset Computer, Bourne, MA, USA) connected to an Onset HOBO Event data logger installed at a $2 \mathrm{~m}$ tower in an open space approximately $50 \mathrm{~m}$ apart from each plot. The funnel-type $G R$ was measured on a weekly basis and was strongly correlated to that of the tipping bucket rain gauge $\left(R^{2}=0.999, p=0.000\right)$; thus, data from the funnel-type rain collector were used in this study.

$T F$ was measured using 30 funnel-type rain collector same for $G R$ in each plot. They were randomly allocated on the forest floor and maintained throughout the study period (Fig. 1). TF $(\mathrm{mm})$ was calculated as follows:

$$
T F=\frac{\sum T F_{i}}{n_{c}}
$$

where $T F_{i}$ is the throughfall (mm) of $T F$ collector $i$ and $n_{c}$ is the number of $T F$ collectors. The data from two $T F$ rain collectors in P1 that normally exceeded $G R$ were excluded for analysis because these $T F$ collectors were placed $\leq 10 \mathrm{~cm}$ from the inclined stems with rough bark and collected not only $T F$ but also separating $S F$ (Levia et al., 2010; Saito et al., 2013). Thus, $n_{c}$ for P1 and P2 were 28 and 30, respectively. The standard relative errors of mean $T F$ estimated using the following equation (Kimmins, 1973; Saito et al., 2013; Shinohara et al., 2013; Sun et al., 2014) for P1 and P2 were $5.0 \%$ and $5.4 \%$, respectively:

$$
\varepsilon=(t \times C V) / \sqrt{n_{c}}
$$

where $\varepsilon$ is the standard relative error of mean $T F, t$ is the Student's t-value for a significance level $(p=0.05)$, and $C V$ is coefficient of variation of $T F$.

$S F$ was measured for nine trees to cover the $D B H$ class at each plot (Fig. 1). Two plastic flexible ducts (diameter $=22 \mathrm{~mm}$ ) with wires were fixed in two lines around the stem at a height of about $1.5 \mathrm{~m}$ to trap $S F$. About $30 \mathrm{~mm}$ of both ducts at the same vertical position were cut and a kitchen hose (diameter $=30 \mathrm{~mm}$ ) was attached in the section to collect $S F$ and drain it to the $S F$ collector. Then, the ducts and part of the hose were surrounded with a transparent vinyl sheet of about $20 \mathrm{~cm}$ width. Silicon sealant was applied on the stem, ducts, hose and vinyl sheet to prevent the leakage of $S F$. The hose was connected to the $S F$ collector made of two connected $90 \mathrm{~L}$ tanks. $S F(\mathrm{~mm})$ was calculated as follows:

$$
S F=\frac{\sum S F V_{i}}{n_{\text {tree }}} \times \frac{N_{\text {tree }}}{P A}
$$

where $S F V_{i}$ is the $S F$ volume (L) of the $S F$ observed trees, $n_{\text {tree }}$ and $N_{\text {tree }}$ are the numbers of $S F$ observed trees (9) and total trees in the plot (50), respectively, and $P A$ is the plot area $\left(200 \mathrm{~m}^{2}\right)$.

$I L(\mathrm{~mm})$ was calculated using the following canopy water balance equation:

$$
I L=G R-T F-S F
$$

Stemflow funneling ratio $\left(F R_{\mathrm{i}}\right)$, the ratio of the volume of stemflow of an individual tree to the gross rainfall delivered on the $B A$ of the tree, was calculated using the following equation (Herwitz, 1986):

$$
F R_{i}=S F V_{i} /\left(G R \times B A_{i}\right)
$$

where $S F V_{i}$ is the volume of $S F$ of an individual tree (L) and $B A_{i}$ is the basal area of the tree $\left(\mathrm{m}^{2}\right)$.

The study was conducted from April to October 2017 during the growing season. During the study period, precipitation amount was $1076.9 \mathrm{~mm}$ which accounted for $65.9 \%$ of the mean annual precipitation. Data were collected once a week. Of 29 data collections, there were no rainfall event for four weeks, a single rainfall event for six weeks, and multiple rainfall events from two to five events for 19 weeks.

\subsection{Data analysis}

First, the relationships between $T F / G R, S F / G R, I L / G R$ and $S D$ were examined with the data in this study with those of 30 data in the previous studies of Japanese coniferous plantations (Japanese cedar and Japanese cypress). We selected the dataset of previous studies in accordance with the five criteria: (1) data of the plantations of Japanese cedar and Japanese cypress in Japan because no essential difference between the two tree species was detected when developing estimation models for $I L$ (Komatsu et al., 2015) and $T F$ (Sun et al., 2017), (2) data supplying all the components of $\mathrm{RP}$, (3) data showing $S D$, (4) data including the typical rainy season of Japan from May to October to avoid substantial variations resulted from a short observation period in RP (Komatsu et al., 2015; Sun et al., 2017), and (5) data without snowfall to exclude the snow partitioning processes. The mean \pm S.D. (range) of the dataset of $S D$ and tree age were $1221 \pm 648(355-2500)$ stems $\mathrm{ha}^{-1}$ and $52 \pm 21(29-92)$ years, respectively (Table S1).

The amount of $G R$ has a significant influence on RP (Staelens et al., 2006; Sun et al., 2015). Thus, the relationships between $G R$ and $T F, S F$, and $I L$ on a weekly basis in P1 and P2 were examined using the least-squares method. Then, $G R$ on a weekly basis was grouped into four classes $(<10,10$ to $<25,25$ to $<50$, and $50 \leq \mathrm{mm}$ ) and the difference of $T F / G R, S F / G R$, and $I L / G R$ between $\mathrm{P} 1$ and $\mathrm{P} 2(\triangle T F / G R, \Delta S F / G R$, and $\Delta I L / G R)$ in each $G R$ class were examined using the Wilcoxon-Mann-Whitney nonparametric test.

The canopy storage capacity $(S, \mathrm{~mm})$, the amount of gross rainfall to fully saturate the canopy, is one of the most important eco-hydrological parameters in RP (Leyton et al., 1967; Link et al., 2004; Sun et al., 2015). Thus, we estimated $S$ using Leyton's method (Leyton et al., 1967). We drew the line with slope $(1-S F / G R)$ in the scattered graph of $G R$ versus $T F(3.0 \mathrm{~mm}<$ $G R<50 \mathrm{~mm}$ ) and shifted it till it enveloped the graph (Shinohara et al., 2013). The $S$ value was obtained from the negative intercept on the $T F$ axis for the upper envelop line (Leyton et al., 1967; Wallace and McJannet, 2006; Shinohara et al., 2013; Saito et al., 2013; Iida et al., 2017).

Finally, we divided each plot of a $20 \mathrm{~m} \times 10 \mathrm{~m}$ into eight sub-plots of $5 \mathrm{~m} \times 5 \mathrm{~m}$ (Fig. 1) and examined the relationship between the dead branch structures and $T F / G R$ using the least-squares method.

Confidence intervals were established at a 0.05 probability level for all statistical analyses with SPSS version 18.0. 


\section{Results}

\subsection{Relationships between $S D$ and RP}

The cumulative $G R$ during the study period was $1076.9 \mathrm{~mm}$. The cumulative $T F, S F$, and $I L$ and their percentage of $G R$ were $493.0 \mathrm{~mm}(45.8 \%), 251.1 \mathrm{~mm}(23.3 \%)$, and $332.8 \mathrm{~mm}$ $(30.9 \%)$ in $\mathrm{P} 1$, respectively and $570.4 \mathrm{~mm}(53.0 \%), 236.1 \mathrm{~mm}$ $(21.9 \%)$, and $270.3 \mathrm{~mm}(25.1 \%)$ in $\mathrm{P} 2$, respectively. Although $S F / G R$ in the two plots were almost the same (1.4 percentage points of difference), $T F / G R$ in $\mathrm{P} 1$ is appreciably smaller (7.2 percentage points) than the one in $\mathrm{P} 2$, resulting in a larger $I L /$ $G R$ in $\mathrm{P} 1$ than that in $\mathrm{P} 2$ (5.8 percentage points).

Fig. 3 shows a comparison of $T F / G R, S F / G R$, and $I L / G R$ against $S D$ obtained in this study with those of 30 data in the previous studies of Japanese coniferous plantations $(n=32$ including the data in this study). $T F / G R$ decreased but the $S F / G R$ and $I L / G R$ increased with increasing $S D$ (Fig. 3). All the components of RP were significantly correlated to $S D: T F / G R$ $\left(R^{2}=0.764, p=0.000\right), S F / G R\left(R^{2}=0.670, p=0.000\right)$, and $I L / G R\left(R^{2}=0.516, p=0.000\right)$, which confirms that $S D$ is an informative stand structure factor for all the RP components in coniferous plantations. Having the highest $S D$ in this study
(Fig. 3), $T F / G R$ were very low: $45.8 \%$ in P1 (lowest) and $53.0 \%$ in $\mathrm{P} 2$ (second lowest), $S F / G R$ were very high: $23.3 \%$ in $\mathrm{P} 1$ (highest) and $21.9 \%$ in $\mathrm{P} 2$ (second highest), and $I L / G R$ were high: $30.9 \%$ in P1 (highest) and 25.1\% (considerably high).

\subsection{Relationships between $\boldsymbol{G R}$ and $\boldsymbol{R P}$ on a weekly basis}

Fig. 4 shows the relationships between $G R$ and RP. Weekly $G R$ ranged from $1.7 \mathrm{~mm}$ to $125.2 \mathrm{~mm}$ with a mean of $43.1 \pm$ $36.3 \mathrm{~mm}$. As with the results of previous studies (e.g., Sun et al., 2015; Shinohara et al., 2015), all the components of RP linearly increased with increasing $G R$ on a weekly basis as follows:

$$
\begin{aligned}
& T F_{1}=0.52 G R-2.45\left(R^{2}=0.97\right) \\
& T F_{2}=0.58 G R-2.33\left(R^{2}=0.99\right) \\
& S F_{1}=0.26 G R-1.17\left(R^{2}=0.97\right) \\
& S F_{2}=0.23 G R-0.48\left(R^{2}=0.92\right) \\
& I L_{1}=0.23 G R+3.62\left(R^{2}=0.81\right) \\
& I L_{2}=0.19 G R+2.80\left(R^{2}=0.83\right)
\end{aligned}
$$

where subscript of 1 and 2 indicates study plots of P1 and P2, respectively.
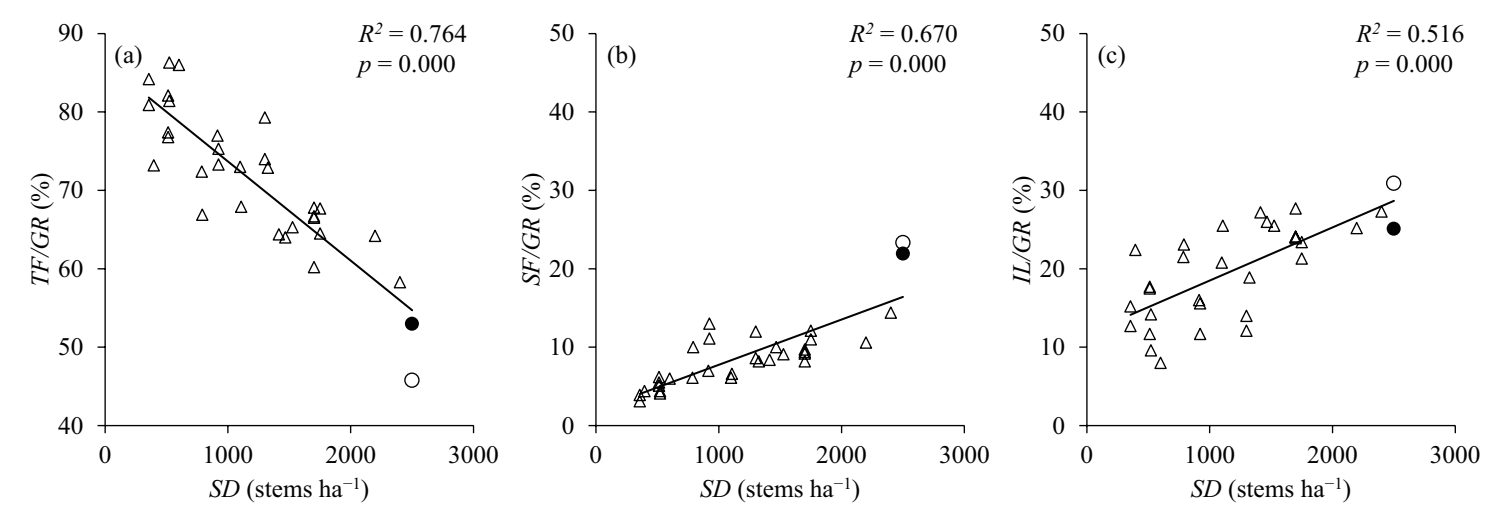

Fig. 3. Relationships between the stand density $(S D)$ and the ratios of each component of RP to gross rainfall in this study with previous studies of Japanese coniferous plantations $(n=32)$ : (a) $T F / G R$, (b) $S F / G R$, and (c) $I L / G R$. The triangles, open circles, and solid circles indicate the ratios in previous studies, the ratio in study plot 1 , and the ratio in study plot 2 , respectively. The solid lines are the regression lines determined by the least-squares method.
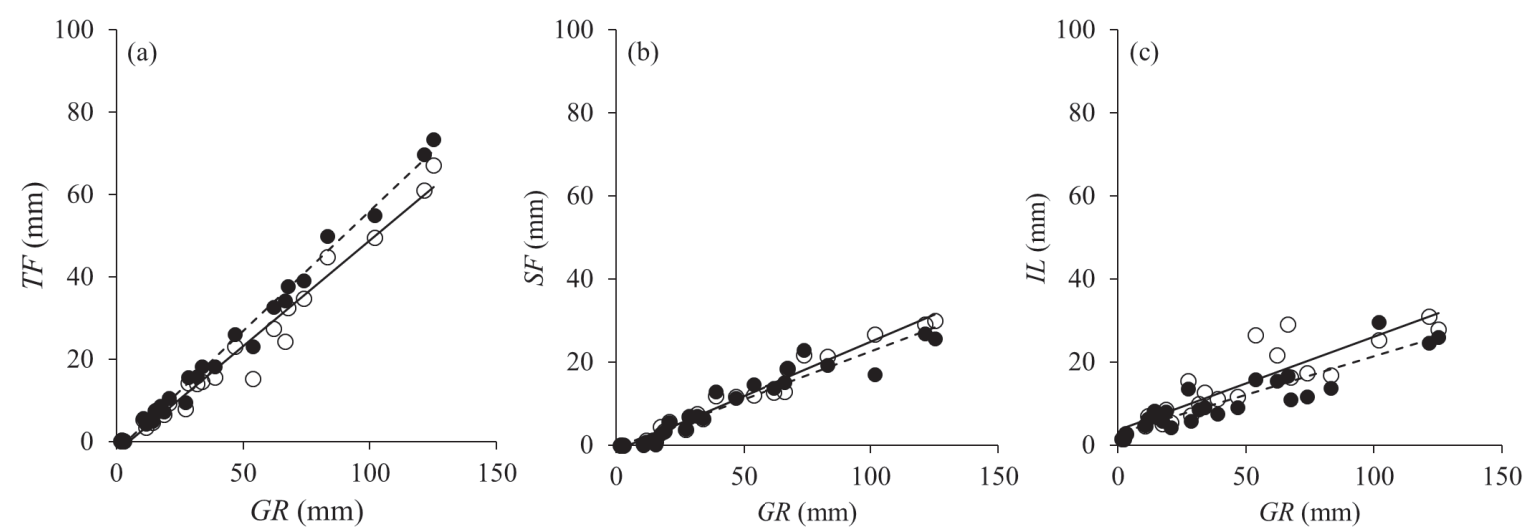

Fig. 4. Relationships between gross rainfall $(G R)$ and each component of RP on a weekly basis: (a) $T F$, (b) $S F$, and (c) $I L$. Open and solid circles indicate the data from the study plot 1 (P1) and study plot 2 (P2), respectively. The solid and dashed lines indicate the linear regression lines of $\mathrm{P} 1$ and $\mathrm{P} 2$ determined by the least-squares method, respectively. 
Table 2. The differences of $T F / G R, S F / G R$ and $I L / G R(\triangle T F / G R, \triangle S F / G R$, and $\Delta I L / G R$ ) between plot 1 (P1) and plot 2 (P2) for four $G R$ classes and total $G R$. Positive values indicate that the ratio in $\mathrm{P} 1$ was larger than that in $\mathrm{P} 2$ and vice versa.

\begin{tabular}{cccccccc}
\hline$G R(\mathrm{~mm})$ & No. of sampling & $\Delta T F / G R(\%)$ & $p$-value & $\Delta S F / G R(\%)$ & $p$-value & $\Delta I L / G R(\%)$ & $p$-value \\
\hline$<10$ & 3 & -2.1 & 1.000 & 0.0 & 1.000 & +2.1 & 1.000 \\
10 to $<25$ & 7 & -4.2 & 0.259 & +3.7 & 0.383 & +0.5 & 1.000 \\
25 to $<50$ & 6 & -6.9 & 0.132 & -0.2 & 0.937 & +7.1 & 0.180 \\
$50 \leq$ & 9 & -7.8 & $0.014 *$ & +1.5 & 0.666 & +6.2 & 0.136 \\
\hline Total & 25 & -7.2 & - & +1.4 & - & +5.8 & - \\
\hline
\end{tabular}

Asterisk denotes $p<0.05$.
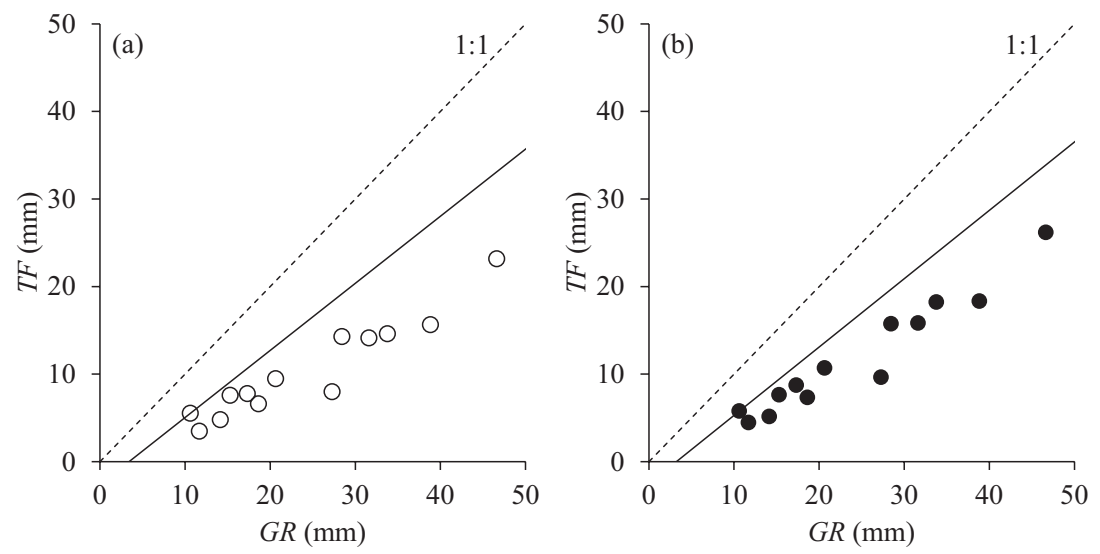

Fig. 5. Relationships between gross rainfall $(G R)$ and throughfall $(T F)$ on a weekly basis in the (a) study plot 1 and (b) study plot 2 , respectively. The solid lines are the upper envelope lines for estimating canopy storage capacity $(S)$.

Table 2 shows the difference of ratios of RP to $G R$ between $\mathrm{P} 1$ and $\mathrm{P} 2(\triangle T F / G R, \triangle S F / G R$, and $\Delta I L / G R)$ in the different rainfall classes on a weekly basis. A positive difference means that the ratio in $\mathrm{P} 1$ was larger than the ratio in $\mathrm{P} 2$ and vice versa. $\triangle S F / G R$ was nearly negligible regardless of the amount of $G R$. On the other hand, $\triangle T F / G R$ was negative indicating $T F / G R$ in $\mathrm{P} 1$ was smaller than that in $\mathrm{P} 2$ while $\triangle I L / G R$ was positive indicating $I L / G R$ in $\mathrm{P} 1$ was larger than that in $\mathrm{P} 2$ in each $G R$ class. The absolute values of $\triangle T F / G R$ and $\triangle I L / G R$ increased with increasing $G R$. However, the difference of $T F / G R$ between $\mathrm{P} 1$ and $\mathrm{P} 2$ was significant only when $G R \geq 50 \mathrm{~mm}(p=0.014$, Mann-Whitney U test).

\subsection{Canopy storage capacity}

Fig. 5 shows the relationship between $G R$ ranging $3-50 \mathrm{~mm}$ and $T F$ on a weekly basis. The solid lines are the upper envelope line for estimating $S$.

$$
\begin{aligned}
& T F_{1}=\left(1-\frac{S F_{1}}{G R}\right) G R-S=0.77 G R-2.63 \\
& T F_{2}=\left(1-\frac{S F_{2}}{G R}\right) G R-S=0.78 G R-2.51
\end{aligned}
$$

From these equations, $S$ values were obtained as $2.63 \mathrm{~mm}$ for P1 and $2.51 \mathrm{~mm}$ for P2, respectively. Compared with $S$ values of the previous studies on Japanese coniferous plantations $(n=13)$ (Table S1), $S$ values of P1 and P2 were the highest and the second highest, respectively.

\subsection{Relationship between dead branches and RP}

The dead branches in P1 outnumbered those in P2 (Fig. 2,
Fig. 6a). The relationship between the average number of dead branch per stem $\left(\overline{N_{d b}}\right)$ and $T F / G R$ in the subplots of P1 and P2 (Fig. 6a) indicates that $T F / G R$ significantly decreased with an increase in $\overline{N_{d b}}$. In the subplots where $\overline{N_{d b}}$ ranged from 45 to 60 branches, however, $T F / G R$ in $\mathrm{P} 2$ tended to be larger than $T F / G R$ in $\mathrm{P} 1$ despite the fact that $\overline{N_{d b}}$ was within the same range (Fig. 6a).

The dead branches in P1 were more densely distributed than those in P2 (Fig. 2), and thus the average vertical dead branch space $\left(\overline{s_{d b}}\right)$ in P1 was shorter than $\overline{s_{d b}}$ in P2. The relationship between $T F / G R$ and $\overline{s_{d b}}$ in the subplots of $\mathrm{P} 1$ and $\mathrm{P} 2$ (Fig. 6b) indicates that $T F / G R$ significantly increased with an increase in $\overline{s_{d b}}$.

Since it was difficult to obtain the representative $S F$ in each subplot, the relationship between the individual number of dead branches and $S F$ funneling ratios $\left(F R_{\mathrm{i}}\right)$ of the sample trees were examined. Clear relationships were found neither between the number of dead branches and $F R_{\mathrm{i}}$ (Fig. 7) nor between individual vertical dead branch spaces and $F R_{\mathrm{i}}$.

\section{Discussion}

\subsection{Stand structures in the dense unmanaged Japanese cypress plantations}

The stem of Japanese cypress is round and grows vertically straight, and its branches grow whirly in a radial direction. Hayashi and Takahashi (1997) measured the directions of branches of 18 Japanese cypress trees at an age of 11 years and reported that the horizontal distribution of the branches was omnidirectional. The average ratio of branch biomass to stem biomass of Japanese cypress $(14.2 \%, n=356)$ was relatively larger compared with those of Japanese cedar $(7.9 \%, n=532)$ and Japanese larch (Larix kaempferi (Lamb.) Carriére) (10.4\%, $n=128$ ) (Hosoda and Ichara, 2010). The branches of Japanese 

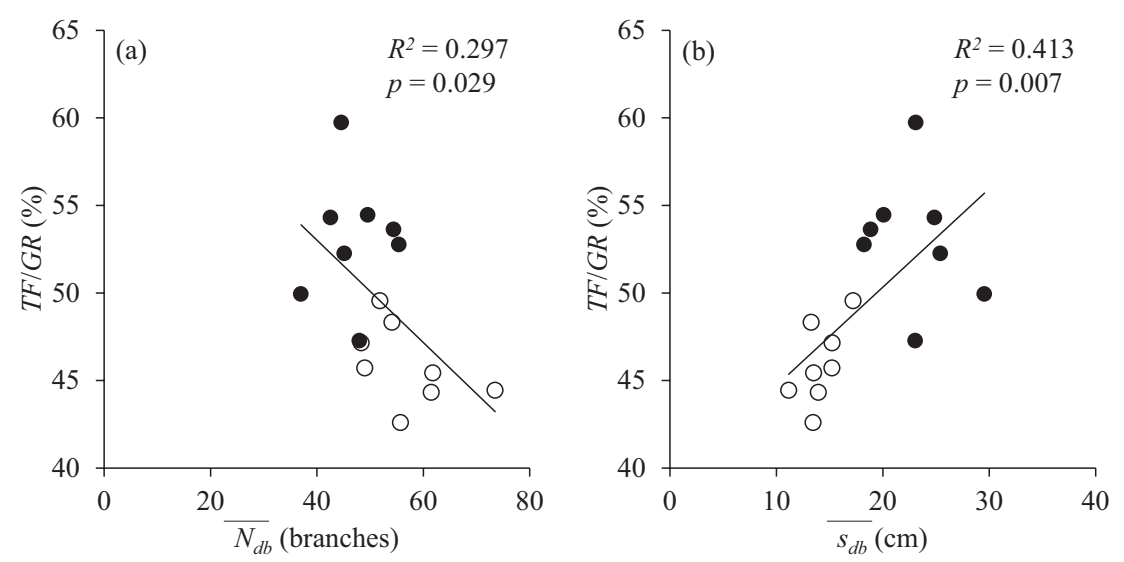

Fig. 6. Relationships (a) between the average number of dead branches $\left(\overline{N_{d b}}\right)$ and the ratio of throughfall to gross rainfall $(T F / G R)$ and $(\mathrm{b})$ between the average dead branch space $\left(\overline{s_{d b}}\right)$ and $T F / G R$ for the 16 subplots, respectively. The open and solid circles indicate the data in the study plot 1 and study plot 2 , respectively. The solid line indicates the regression line determined by the least-squares method.

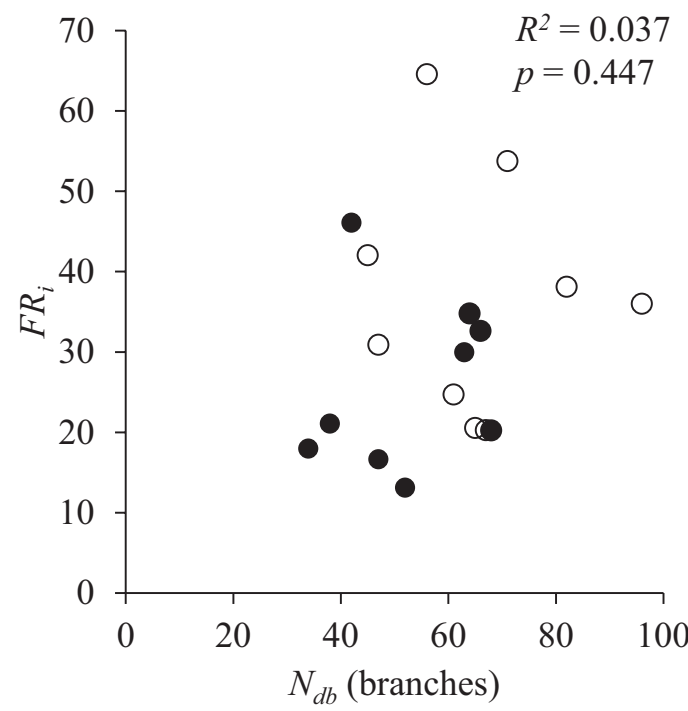

Fig. 7. The relationship between the number of dead branches $\left(N_{d b}\right)$ and the individual funneling ratio $\left(F R_{\mathrm{i}}\right)$. The open and solid circles indicate the study plot 1 and study plot 2 , respectively.

cypress have long life spans with unexpectedly long stunted periods. Fujimori (1993) measured the dynamics of crown structure and stem growth of a Japanese cypress tree at an age of 51 years without artificial pruning and found that the life span of branches was about 16 years on average: nine years of growing period and seven years of stunted period. In addition to the long life span of branches, the dead branches of Japanese cypress tend to stay on the stem while those of Japanese cedar tend to naturally drop. Otake et al. (2007) measured the canopy structures of four cut trees of Japanese cypress with different ages of $19-34$ years and heights of $7.0-15.3 \mathrm{~m}$ and reported that (1) the vertical space between the branches were consistently about $5 \mathrm{~cm}$ from top of the trees to the lowest dead branches near the forest floor, and (2) the lengths of branches ranged up to $3 \mathrm{~m}$ and its average vertical distribution was approximated by the quadratic equation having its vertex at half the tree height. Moreover, the branches tend to stay longer in dense Japanese cypress stands possibly because the wind speeds within the canopy in dense coniferous plantation were weaker than those in sparse plantations (Suzuki et al., 2010). Based on the results of Inagaki et al. (2010) investigating the effects of typhoons on the branch falls of Japanese cypress plantations at an age of 23 years with some 46 years-old trees, the branch falls in the control plot without thinning with a $S D$ of 1700 stems ha $^{-1}$ was about $1 / 3$ of that in the thinning plot with a $S D$ of 850 stems ha $^{-1}$. These results imply that the dense and thick dead branch layers from the base of the crown to near the forest floor are common features of unmanaged Japanese cypress plantations.

$S D$ studied in most of the previous studies on RP of two dominant coniferous plantations in Japan (Japanese cedar and Japanese cypress) ranged less than 2000 stems ha $^{-1}$ (Fig. 3). These stands should be thinned once or more because $S D$ was less than the general planting density, which implies that these stands should be pruned during the course of silvicultural practice with thinning. Consequently, there are very few studies on RP in dense unmanaged coniferous plantations in Japan despite the fact that they are widely distributed in Japan. Conversely, the stands in this study have the typical stand structures of unmanaged Japanese cypress plantations as mentioned above and thus could contribute new information to the studies on RP in coniferous plantations.

The stands in this study were almost fully covered with canopies where $C C$ were $99.3 \%$ in P1 and $99.6 \%$ in P2 (Table 1), which indicates that the free throughfall was negligible in each plot: free $T F$ coefficients $\left(C_{\mathrm{FTF}}\right)$ were $0.7 \%$ in $\mathrm{P} 1$ and $0.4 \%$ in $\mathrm{P} 2$. Consequently, most of the rainwater in this study should be at least once re-intercepted (Nanko et al., 2008b, 2011) and RP should occur not only in the crown composed of leaves and live branches but also in the thick and dense dead branch layers below the crown.

\subsection{Comparison of RP in coniferous plantations in Japan with the previous studies}

For all the RP components, $S D$ was a significantly informative stand structure factor (Fig. 3). However, there could be other stand structure factors influencing RP in addition to $S D$. 
There are studies reported that $S D, C C, B A$, and $P A I$ were the dominant stand structure factors affecting $T F$ and $I L$ (Teklehaimanot et al., 1991; Toba and Ohta, 2002; Molina and del Campo, 2012; Komatsu et al., 2015; Sun et al., 2017). $S$ was also considered as an informative factor on $T F$ and $I L$ under the different stand structures of $S D$ and CC (Leyton et al., 1967; Link et al., 2004; Saito et al., 2013; Sun et al., 2015). SD in this study were the highest $\left(2500\right.$ stems $^{-1}$ ) among the previous studies on RP in coniferous plantations in Japan (Fig. 3). On the other hand, $S$ in P1 was higher than that in P2 though the both $S$ values in this study were very high compared with the previous reported values: $2.63 \mathrm{~mm}$ in $\mathrm{P} 1$ (highest) and $2.51 \mathrm{~mm}$ in $\mathrm{P} 2$ (Table S1). $B A$ is the factor representing the stem area measured by $D B H$, and $C C$ and $P A I$ are factors representing the canopy coverage and plant area measured by the light transmittance of the canopy, respectively. Therefore, these factors are indirectly related to RP but cannot directly represent the RP. On the other hand, $S$ was calculated by the measured RP data and thus directly related to RP. We obtained the significant relations between $\mathrm{RP}$ and $S$ from the data in Table $\mathrm{S} 1$ as follows: (1) $T F / G R$ : $R^{2}=0.662, \quad p=0.001 ; \quad(2) \quad S F / G R: \quad R^{2}=0.356, \quad p=0.031$; (3) $I L / G R: R^{2}=0.676, p=0.001$. Therefore, the lowest $T F / G R$, the highest $S F / G R$ and the highest/considerably high $I L / G R$ in this study could be explained by the virtually full $C C$ and highest $S$ values in addition to the highest $S D$. Although the stand structure of thick and dense dead branch layers in P1 and $\mathrm{P} 2$ could also cause the extreme ratios of RP to $G R$ (low $T F / G R$, high $S F / G R$, and high $I L / G R$ ) in this study, discussions on this possibility by comparing with the previous studies cannot be conducted because there have not been any studies on the effects of dead branches on RP at the stand scale.

\subsection{Comparison of RP between the two dense unmanaged Japanese cypress plots}

P1 and P2 had the trees at the same age of 33 years with the same $S D$ of 2500 stems $^{-1}$ and the similar extreme ratios of RP to $G R$ (low $T F / G R$, high $S F / G R$, and high $I L / G R$ ) compared with the previous studies (Fig. 3). In detail, however, the stand structures and the ratios of RP to $G R$ in $\mathrm{P} 1$ and $\mathrm{P} 2$ were slightly different. Since all the components of RP and overall stand structure factors including dead branch distributions were measured in this study, comparisons of the stand structure and RP between P1 and P2 could contribute new knowledge to the studies on RP in coniferous plantations.

\subsection{1 $T F$ in dense unmanaged Japanese cypress plantations}

$T F / G R$ in $\mathrm{P} 1$ and $\mathrm{P} 2$ were $45.8 \%$ and $53.0 \%$, respectively. Although they were the lowest and second lowest compared with $T F / G R$ in the previous studies, the difference was considerably large as $T F / G R$ in $\mathrm{P} 1$ was 7.2 percentage points lower than that in P2 (Table 2). Although $T F / G R$ in P2 followed the relationship between $T F / G R$ and $S D$ in the previous studies, that in $\mathrm{P} 1$ was exceptionally low (Fig. 3a). $T F / G R$ in $\mathrm{P} 2$ was estimated by the $T F$ model for coniferous plantations in Japan using $S D, B A$, and $C C$ (Sun et al., 2017) with an estimation error of 1.6 percentage points. On the other hand, the estimation error of $T F / G R$ in $\mathrm{P} 1$ was 6.1 percentage points lower, which exceeded the relative error of the $T F$ model $(3.2 \pm 2.4 \%)$. The results imply that there could be some stand structure factors other than the common stand structure factors such as $S D, C C$, and $B A$ for estimating $T F / G R$ (Molina and del Campo, 2012; Sun et al., 2017) in dense unmanaged coniferous plantations.

The free throughfall, drip, and splash from the crown should be similar in each plot because the crown and live branch structures in P1 and P2 were almost the same (Table 1, Fig. 2). However, RP below the crown should be different between P1 and P2 because the dead branch structures were considerably different (Fig. 2). The parts of raindrops could be re-intercepted, re-captured, re-dripped, and splashed by the dead branches. In this study, P2 had approximately 0.8 times less $\overline{N_{d b}}$ and 1.6 times longer $\overline{s_{d b}}$, respectively. $T F / G R$ in $\mathrm{P} 2$ was larger than that in $\mathrm{P} 1$ possibly because of less re-interception of raindrops by the less $\overline{N_{d b}}$ and more splash generation induced by the longer $\overline{s_{d b}}$ (Fig. 6). Splash occurred in the canopy contributes not only to TF (Nanko et al., 2006; Levia et al., 2017) but also to $I L$ transferred into the atmosphere (Murakami, 2006; Saito et al., 2013). However, the splash occurred on the dead branches under the crown in the dense stands could contribute mostly to $T F$ but not to $I L$ because wind speed within the canopy in the dense stands are very weak compared with the wind above the canopy (Nakai et al., 2008; Kitagawa et al., 2010; Suzuki et al., 2010). Thus, the dead branch structures could be other informative factors for $T F / G R$ in addition to $S D, C C, B A$, and $S$ in dense unmanaged coniferous plantations, especially in Japanese cypress plantations.

There were several studies on the relationship between live branches and $T F$ supporting the above-mentioned discussion. Staelens et al. (2006) found that the branch cover was correlated to $T F$ during a leafed period in a beech (Fagus sylvatica L.) stand and the $T F$ decreased with increasing branch cover. He et al. (2014) found that plant area (leaf area plus wood area) rather than leaf area alone affected $T F$. Nanko et al. (2008b) conducted the pruning experiment on $T F$ of Japanese cypress and reported that the thicker canopy had higher possibility for re-interception and splash by lower canopy layers. Nanko et al. (2011) reported that spatial distribution of $T F$ was dominated by the canopy structure and position of branches inside the canopy. There were also several studies on the relationship between dead branches and $T F$ supporting the above-mentioned discussion. Hutchings et al. (1988) found that the dead branches under the canopy stayed on the lower part of the stems had approximately $17 \%$ of total $S$ for Sitka spruce (Picea sitchensis (Bong.) Carr.), which implies that the dead branches could recapture decent amount of rainwater. Nanko et al. (2008a) suggested that drips could be generated not only from the leaves on living branches but also from the dead branches in a mature Japanese cypress plantation based on the results that some drips had lower velocity/kinetic energy than those of expected drip falling from the crown-base height, which implies that the dead branches played a role in re-capture and re-drip. Shinohara et al. (2018) found that the drop velocity/kinetic energy decreased with decreasing in height of the lowest dead branch in Japanese cypress plantations, which implies that the shorter falling distance could decrease splash generation. Therefore, the results of the present study with these previous studies suggest that the dead branches should play an important role in $T F$ generation. 


\subsection{2 $S F$ in dense unmanaged Japanese cypress plantations}

$S F / G R$ in $\mathrm{P} 1$ and $\mathrm{P} 2$ were exceptionally high compared with $S F / G R$ in the previous studies (Fig. 3b): $23.3 \%$ in P1 (highest) and $21.9 \%$ in P2 (second highest). They were about three times higher than the average of previous $S F / G R$ (Fig. 3b) and about two times higher than average $S F / G R$ reviewed by Levia and Frost (2003) and Levia and Germer (2015).

$S F$ and TF generated in the crowns should be similar in P1 and P2 because the crown structures were almost the same. However, their process under the crown could be different. $S F$ from the crown could flow on the stems and reach to the forest floor without obstacles. On the other hand, $T F$ from the crown could be intercepted by the dead branches while falling (Shinohara et al., 2018). When the intercepted $T F$ accumulates enough to saturate the branches, subsequently rainwater flows from the branches to the stems could be generated (Nanko et al., 2011) in addition to the drip and splash. This additional $S F$ generated by the dead branches could be the predominant reason why $S F / G R$ in this study were exceptionally high because of a number of dead branches.

However, the $S F$ funneling ratios $\left(F R_{i}\right)$ had no clear relationship with $N_{d b}$ of each $S F$ measured tree while $T F / G R$ in the subplots had a clear positive relationship with $\overline{N_{d b}}$. Moreover, $S F / G R$ in $\mathrm{P} 1$ and $\mathrm{P} 2$ were almost identical regardless of $G R$ class while the difference of $T F / G R$ between $\mathrm{P} 1$ and $\mathrm{P} 2$ increased with increasing $G R$ (Table 2).

Sufficient rainwater is necessary to generate $S F$ at the dead branches because the rainwater movement in the canopies generally occurs in the sequence of saturation, dripping, and flowing (Nanko et al. 2011). The higher dead branches could intercept and store the rainwater composed of raindrops, drips, and splash more easily and thus get wetter than the lower dead branches because the rainwater in higher position has smaller kinetic energy with slower falling velocity (Nanko, 2013). Therefore, the dead branches generating $S F$ should be limited to the upper dead branches, and the lower dead branches could not accumulate enough $T F$ to generate rainwater flow at the branches regardless of the number of branches. These discussions could be the influential reason why the relationship between $F R_{i}$ and $N_{d b}$ was not clear (Fig. 7) and $S F / G R$ in P1 and P2 were almost identical (Table 2). These results suggest that the dead branches under the crown could increase $S F$ but the dead branches generating $S F$ could be limited to the upper dead branches.

There were several previous studies on the relationship between $S F$ and the branch structures supporting the above-mentioned discussions. There were reports mentioning that $S F$ increased with increasing the number of branches using 12 European beech saplings (Levia et al., 2015), 30 shrubs belonging to three species (Návar, 1993), 14 shrubs belonging to two species (Yang et al., 2008), and 129 trees belonging to 33 species (Honda et al., 2015), which corresponds with our results although the branches of these studies were alive. There were reports mentioning that $S F$ was larger during the leafless season than during the leaved season using eight beech trees and 6-11 oak (Quercus petraea Liebl.) trees (André et al., 2008), seven deciduous trees (Mużylo et al., 2012), and a cylindrical lath-turned pine post with a diameter of $75 \mathrm{~mm}$ and length of $1.2 \mathrm{~m}$ having the branches with a diameter of 8, 16, and $25 \mathrm{~mm}$ and length of $22 \mathrm{~cm}$ (Dunkerley, 2014), which implies that not only leaves but also woody parts of the tree including branches plays an important role in generating $S F$. Kuraji et al. (2001) measured the crown-only $S F$ and stem-only $S F$ of a Japanese cypress tree at an age of 70 years and with a height of 28.8 $\mathrm{m}$ and found that stem-only $S F$ increased with increasing $G R$ up to about $20 \%$ of the whole $S F$, which implies that a relatively large $S F$ can be generated below the crown. $S F$ increased with increase in steepness of the branch angle toward the sky (Levia and Frost, 2003; Futatsuka, 2008; Levia et al., 2015; Levia and Germer, 2015). Most of the branches of Japanese cypress were up-facing (Nanko et al., 2011; Kawatani et al., 2012), but the branch angle gradually decreased from the higher canopy to the lower canopy and some of the branches in the lower canopy were down-facing (Nanko et al., 2011), which implies that $S F$ on the dead branches could occur mostly in the upper dead branches. Therefore, the results of the present study with these previous studies suggest that the dead branches should play an important role in $S F$ generation.

\section{Conclusion}

We observed all the components of rainfall partitioning (RP) into throughfall $(T F)$, stemflow $(S F)$, and interception loss $(I L)$, and all stand structure factors including the dead branch structures in the two dense unmanaged Japanese cypress plots with the same stand density $(S D)$ of 2500 stems ha $^{-1}$, and the results were compared with the previous studies on RP in two dominant coniferous plantations (Japanese cedar and Japanese cypress) in Japan. The relationships between stand structures and RP in coniferous plantations obtained in this study were as follows:

\subsection{Relationship between $S D$ and RP in coniferous plantations}

$T F / G R$ significantly decreased with increasing $S D$ while $S F / G R$ and $I L / G R$ significantly increased with increasing $S D$, which confirms that $S D$ is an informative stand structure factor for all the RP components in coniferous plantations. Having the highest $S D, T F / G R$ were the lowest and second lowest, $S F / G R$ were the highest and second highest, and $I L / G R$ were the highest and considerably high in the two study plots. In addition to $S D$, canopy cover ratio $(C C)$ and storage capacity $(S)$ could also be influential stand structure factors for RP.

\subsection{Difference of RP in the two dense unmanaged coniferous plantations}

Although the two study plots had the same $S D$ and the similar extreme ratios of RP to $G R$ (low $T F / G R$, high $S F / G R$, and high $I L / G R$ ) compared with the previous studies, the stand structures and the ratios were slightly different. The plot with smaller stand with denser and thicker dead branch layers had exceptionally low $T F / G R$ compared with the other plot, but $S F / G R$ in both plots were almost identical and exceptionally high.

\subsection{New stand structure factors affecting RP in coniferous plantations}

$T F / G R$ decreased with increasing average number of dead branches $\left(\overline{N_{d b}}\right)$ possibly because of increasing interception by dead branches, while it increased with increasing average dead branch space $\left(\overline{s_{d b}}\right)$ possibly because of increasing splash by dead branches. $S F / G R$ could increase by dead branches possibly because of the 
additional gain of rainwater by the dead branches. However, $N_{d b}$ did not influence $S F / G R$ possibly because the dead branches generating $S F$ could be limited to the upper dead branches.

The above-mentioned findings on the relationship between stand structures and RP will contribute new knowledge to the studies on RP in coniferous plantations and guide better silvicultural practices for effective forest ecological services. Pruning experiment and measuring raindrop diameter will be helpful to confirm the findings.

\section{Acknowledgements}

We acknowledge the staffs of Kasuya Research Forest of Kyushu University and the faculties and students of the laboratory of forest ecosystem management for their help for measurement. We also thank Drs. Yoshinori Shinohara (Miyazaki University) and Akio Inoue (Prefectural University of Kumamoto) for their fruitful advice and comments. This study was partly supported by JSPS KAKENHI Grant number JP26292088, JP18H04152.

\section{References}

André F, Jonard M, Ponette Q, 2008: Influence of species and rain event characteristics on stemflow volume in a temperate mixed oak-beech stand. Hydrological Processes 22, 4455-4466.

Carlyle-Moses DE, Price AG, 1999: An evaluation of the Gash interception model in a northern hardwood stand. Journal of Hydrology 214, 103-110.

Dunkerley D, 2014: Stemflow on the woody parts of plants: dependence on rainfall intensity and event profile from laboratory simulations. Hydrological Processes 28, 5469-5482.

Fujimori T, 1993: Dynamics of crown structure and stem growth based on knot analysis of a hinoki cypress. Forest Ecology and Management 56, 57-68.

Futatsuka Y, 2008: The amount of stemflow and its analysis. In The actual condition of plantation devastation on water and soil erosion (ed. by Onda Y). Iwanami Shoten, Tokyo, pp. 23-31 (in Japanese).

Gash JHC, 1979: An analytical model of rainfall interception by forests. Quarterly Journal of the Royal Meteorological Society 105, 43-55.

Hayashi S, Takahashi Y, 1997: On the modelling of tree's figure - Case of Cryptomeria japonica and Chamaecyparis obtuse-. Journal of the Japanese Forest Society 79, 222-228 (in Japanese with English abstract).

He ZB, Yang JJ, Zhao WZ, Liu H. Chang XX, 2014: Spatial variability of canopy interception in a spruce forest of the semiarid mountain regions of China. Agricultural and Forest Meteorology 188, 58-63.

Herwitz SR, 1986: Infiltration-excess caused by stemflow in a cyclone-prone tropical rainforest. Earth Surface Processes and Landforms 11, 401-412.

Honda EA, Mendonca AH, Durigan G, 2015: Factors affecting the stemflow of trees in the Brazilian Cerrado. Ecohydrology $\mathbf{8}$, 1351-1362.

Hörmann G, Branding A, Clemen T, Herbst M, Hinrichs A, Thamm F, 1996: Calculation and simulation of wind controlled canopy interception of a beech forest in northern Germany. Agricultural and Forest Meteorology 79, 131-148.

Hosoda K, Ichara T, 2010: Above ground biomass equations for individual trees of Cryptomeria japonica, Chamaecyparis obtusa and Larix kaempferi in Japan. Journal of Forest Research 15, 299-306.

Hutchings NJ, Milne R, Crowther JM, 1988: Canopy storage capacity and its vertical distribution in a Sitka spruce canopy. Journal of Hydrology 104, 161-171.

Iida S, Levia DF, Shimizu A, Shimizu T, Tamai K, Nobuhiro T, Kabeya N, Noguchi S, Sawano S, Araki M, 2017: Intrastorm scale rainfall interception dynamics in a mature coniferous forest stand. Journal of Hydrology 548, 770-783.

Inagaki Y, Kuramoto S, Fukuta H, 2010: Effects of typhoons on leaf fall in hinoki cypress (Chamaecyparis obtuse Endlicher) plantations in Shikoku Island. Bulletin of the Forestry and Forest Products Research Institute 9, 103-112.

Japan Forestry Agency, 1957: Preparation Manual of Stand Yields of Japanese Cypress in Kyushu District, Japan Forestry Agency, Kumamoto, pp. 49 (in Japanese).

Japan Forestry Agency, 2017: Annual Report on Forest and Forestry in Japan Fiscal Year 2016 (Summary), Ministry of Agriculture, Forestry and Fisheries, Japan, Tokyo, Available from http:/www.rinya.maff.go.jp/j/kikaku/hakusyo/28hakusyo/ attach/pdf/index-1.pdf (accessed May 2018), pp. 30.

Kawatani S, Kobayashi H, Seino T, 2012: Crown architecture of Chamaecyparis obtusa and C. pisifera samplings growing in a closed forest floor. Bulletin of Shinshu University Alpine Field Center 10, 85-90 (In Japanese with English Abstract).

Kimmins JP, 1973: Some statistical aspects of sampling throughfall precipitation in nutrient cycling studies in British Columbian coastal forests. Ecology 54, 1008-1019.

Kinoshita K, Takimoto K, 1936: Geology around the forests affiliated to the Faculty of Agriculture, Kyushu Imperial University, Bulletin of the Kyushu Imperial University Forest 9, 1-71 (in Japanese).

Kitagawa K, Kamimura K, Saito S, Uchida T, Mizunaga H, 2010: Wind profile and mechanical resistance of uprooted trees in a Japanese cypress (Chamaecyparis obtusa) plantation slightly damaged by Typhoon Melar 0918 at Kamiatago Experimental Forest, Tenryu Japan: Validity of mechanistic model for wind damage risk. Japanese Journal of Forest Environment 52, 57-66.

Komatsu H, Shinohara Y, Kume T, Otsuki K, 2008: Relationship between annual rainfall and interception ratio for forests across Japan. Forest Ecology and Management 256, 1189-1197.

Komatsu H, Shinohara Y, Otsuki K, 2015: Models to predict changes in annual runoff with thinning and clearcutting of Japanese cedar and cypress plantations in Japan. Hydrological Processes 29, 5120-5134.

Komatsu H, Tanaka N, Kume T, 2007: Do coniferous forests evaporate more water than broad-leaved forests in Japan? Journal of Hydrology 336, 361-375.

Kuraji K, Tanaka Y, Tanaka N, Karakama I, 2001: Generation of stemflow and chemistry in a mature Japanese cypress forest. Hydrological Processes 15, 1967-1978.

Kuraji K, 2003: Effects of forests on stabilizing streamflow. Nihon chisan-chisui Kyokai, Tokyo (in Japanese).

Leyton L, Reynolds ERC, Thompson FB, 1967: Rainfall interception in forests and moorland. In International Symposium on Forest Hydrology (ed. by Sooper WE, Lull HW). Pergamon Press, New York, pp.163-178.

Levia DF, Frost EE, 2003: A review and evaluation of stemflow literature in the hydrologic and biogeochemical cycles of forested and agricultural ecosystems. Journal of Hydrology 274, 1-29.

Levia DF, Van Stan II JT, Mage SM, Kelley-Hauske PW, 2010: Temporal variability of stemflow in a beech-yellow poplar 
forest in relation to tree species and size. Journal of Hydrology 380, 112-120.

Levia DF, Michalzik B, Näthe K, Bischoff S, Richter S, Legates DR, 2015: Differential stemflow yield from European beech saplings: the role of individual canopy structure metrics. Hydrological Processes 29, 43-51.

Levia DF, Germer S, 2015: A review of stemflow generation dynamics and stemflow-environment interactions in forests and shrublands. Reviews of Geophysics 53, 673-714.

Levia DF, Hudson SA, Llorens P, Nanko K, 2017: Throughfall drop size distributions: a review and prospectus for future research, WIREs Water 4, e1225.

Link ET, Unsworth M, Marks D, 2004: The dynamics of rainfall interception by a seasonal temperate rainforest. Agricultural and Forest Meteorology 124, 171-191.

Llorens P, Poch R, Latron J, Gallart F, 1997: Rainfall interception by a Pinus sylvestris forest patch overgrown in a Mediterranean mountainous abandoned area. 1. Monitoring design and results down to the event scale. Journal of Hydrology 199, 331-345.

Llorens P, Domingo F, 2007: Rainfall partitioning by vegetation under Mediterranean conditions. A review of studies in Europe. Journal of Hydrology 335, 37-54.

Molina AJ, del Campo AD, 2012: The effects of experimental thinning on throughfall and stemflow: A contribution towards hydrology-oriented silviculture in Aleppo pine plantations. Forest Ecology and Management 269, 206-213.

Murakami S, 2006: A proposal for a new forest canopy interception mechanism: Splash droplet evaporation. Journal of Hydrology 319, 72-82.

Mużylo A, Llorens P, Domingo F, 2012: Rainfall partitioning in a deciduous forest plot in leafed and leafless periods. Ecohydrology 5, 759-767.

Nakai T, Sumida A, Matsumoto K, Daikoku K, Iida S, Park H, Miyahara M, Kodama Y, Kononov AV, Maximov TC, Yabuki H, Hara T, Ohta T, 2008: Aerodynamic scaling for estimating the mean height of dense canopies. Boundary-Layer Meteorology 128, 423-443.

Nanko K, Hotta N, Suzuki M, 2006: Evaluating the influence of canopy species and meteorological factors on throughfall drop size distribution. Journal of Hydrology 329, 433-431.

Nanko K, Mizugaki S, Onda Y, 2008a: Estimation of soil splash detachment rates on the forest floor of an unmanaged Japanese cypress plantation based on field measurements of throughfall drop sizes and velocities. Catena 72, 348-361.

Nanko K, Onda Y, Ito A, Moriwaki H, 2008b: Effect of canopy thickness and canopy saturation on the amount and kinetic energy of throughfall: An experimental approach. Geophysical Research Letters 35, L05401.

Nanko K, Onda Y, Ito A, Moriwaki H, 2011: Spatial variability of throughfall under a single tree: Experimental study of rainfall amount, raindrops, and kinetic energy. Agricultural and Forest Meteorology 151, 1173-1182.

Nanko K, 2013: Relationship between throughfall kinetic energy and tree height, crown bottom height, and crown length for Japanese cypress plantation. Journal of the Japanese Forest Society 95, 234-239 (in Japanese with English abstract).

Návar J, 1993: The cause of stemflow variation in three semi-arid growing species of northern Mexico. Journal of Hydrology 145, 175-190.

Onda Y, Gomi T, Mizugaki S, Nonoda T, Sidle RC, 2010: An overview of the field and modeling studies on the effect of forest devastation on flooding and environmental issues.
Hydrological Processes 24, 527-534.

Otake N, Takase K, Ebisu N, 2007: Estimation of water storage capacity on branches of Japanese cedar and cypress by modelling tree form. Journal of Japan Society of Hydrology and Water Resources 20, 424-431 (in Japanese with English abstract).

Sadeghi SMM, Van Stan JT, Pypker TG, Tamjidi J, Freisen J, Farahnaklangroudi M, 2018: Importance of transitional leaf states in canopy rainfall partitioning dynamics. European Journal of Forest Research 137 1-10.

Saito T, Matsuda H, Komatsu M, Xiang Y, Takahashi A, Shinohara Y, Otsuki K, 2013: Forest canopy interception loss exceeds wet canopy evaporation in Japanese cypress (Hinoki) and Japanese cedar (Sugi) plantations. Journal of Hydrology 507, 287-299.

Shinohara Y, Ide J, Higashi N, Komatsu H, Kume T, Chiwa M, Otsuki K, 2010: Observation of canopy interception loss in an abandoned coniferous plantation. Journal of the Japanese Forest Society 92, 54-59 (in Japanese with English abstract).

Shinohara Y, Komatsu H, Kuramoto K, Otsuki K, 2013: Characteristics of canopy interception loss in Moso bamboo forests in Japan. Hydrological Processes 27, 2041-2047.

Shinohara Y, Levia DF, Komatsu H, Nogata M, Otsuki K, 2015: Comparative modeling of the effects of intensive thinning on canopy interception loss in a Japanese cedar (Cryptomeria japonica D. Don) forest of western Japan. Agricultural and Forest Meteorology 214-215, 148-156.

Shinohara Y, Ichinose K, Morimoto M, Kubota T, Nanko K, 2018: Factors influencing the erosivity indices of raindrops in Japanese cypress plantations. Catena 171, 54-61.

Staelens J, De Schrijver A, Verheyen K, Verhoest NEC, 2006: Spatial variability and temporal stability of throughfall water under a dominant beech (Fagus sylvatica L.) tree in relationship to canopy cover. Journal of Hydrology 330, 651-662.

Sun X, Onda Y, Kato H, 2014: Incident rainfall partitioning and canopy interception modelling for an abandoned Japanese cypress stand. Journal of Forest Research 19, 317-328.

Sun X, Onda Y, Kato H, Gomi K, Komatsu H, 2015: Effect of strip thinning on rainfall interception in a Japanese cypress plantation. Journal Hydrology 525, 607-618.

Sun X, Onda Y, Kato H, Gomi T, Liu X, 2017: Estimation of throughfall with changing stand structures for Japanese cypress and cedar plantations. Forest Ecology and Management 402, 145-156.

Suzuki S, Yoshitake T, Goto Y, 2010: Estimation of wind load on trees in forest, Kanto Journal of Forest Research 61, 215-218 (in Japanese).

Tange K, Koike T (ed.), 2016: Silviculture, Asakura Shoten, Tokyo, pp.192 (in Japanese).

Teklehaimanot Z, Jarvis PG, Ledger DC, 1991: Rainfall interception and boundary-layer conductance in relation to tree spacing. Journal of Hydrology 123, 261-278.

Toba T, Ohta T, 2002: Modeling the characteristics of interception loss in forests. Journal of Japan Society of Hydrology and Water Resources 15, 345-362 (in Japanese with English abstract).

Wallace J, McJannet D, 2006: Modelling interception in coastal and montane rainforest in northern Queensland, Australia. Journal of Hydrology 348, 480-495.

Yang ZP, Li XY, Liu LY, Wu JJ, Hasi E, Sun YL, 2008: Characteristics of stemflow for stand-fixed shrubs in $\mathrm{Mu}$ Us sandy land, Northwest China. Chinese Science Bulletin 53, 2207-2214. 